\title{
Valoración ecónomica ambiental: el problema del costo social
}

\section{RESUMEN}

La valoración económica ambiental pretende obtener una medición monetaria de la ganancia o pérdida de bienestar 0 utilidad que una persona, 0 un determinado colectivo experimenta, a causa de una mejora o daño de un activo ambiental accesible a dicha persona o colectivo.

El estudio concluye que las componentes del ambiente cumplen funciones que permiten mantener las condiciones de los ecosistemas y del ambiente, por lo que el Estado establece mecanismos para valorizar los servicios ambientales, procurando lograr la conservación de los ecosistemas, la diversidad biológica y los demás recursos naturales.

Palabras clave: desarrollo sostenible, economía ambiental, economía ecológica, externalidades económicas, manejo ambiental

ENVIRONMENTAL ECONOMIC VALUATION: THE PROBLEM OF SOCIAL COST

\section{ABSTRACT}

Environmental economic valuation seeks a monetary measurement of the gain or loss of welfare or utility that an individual or a particular group experience, because of improved or damaged environmental asset accessible to such person or group.

The study concludes that the environmental components perform functions that maintain the conditions of ecosystems and the atmosphere, so that the State establishes mechanisms to enhance environmental services, seeking to ensure the conservation of ecosystems, biodiversity and other resources natural.

Keywords: ecological economics, economic externalities, environmentaleconomics, environmental management, sustainable development

\section{SITUACION PROBLEMÁTICA}

La constante búsqueda por el desarrollo sostenible y el adecuado manejo ambiental, es hoy en la actualidad, un reto que involucra a todos y especialmente a todas las ramas del conocimiento: un problema de alcance global, de carácter intergeneracional (Comunidad Andina, agosto 2007).

La ciencia económica está dedicada a establecer métodos de valoración monetaria, para cuantificar el deterioro ambiental. El objetivo de estas herramientas de análisis es valorar el medio ambiente evidenciando su "valor" como bien público. Dicho valor se mediría, en principio, por la voluntad de las personas a pagar por él. Se trata de precisar qué es lo que la una persona realmente desea antes que simplemente ignorar sus preferencias.

El cálculo de la disponibilidad para pagar de las personas por un bien es observable cuando hacen sus compras; no existen mercados donde se compren o vendan unidades de activos ambientales. No hay un "mercado del ruido" o un "mercado de calidad del aire", se hace necesario utilizar los métodos desarrollados por la Economía Ambiental para medir los beneficios de una mejora en la calidad ambiental.

En la investigación de Manuel Glave y Rodrigo Pizarro (2001), para el proyecto IRG/BIOFOR con asistencia de INRENAy USAID, se destaca: "Desde el punto de vista económico, los bienes y servicios ambientales son tratados como bienes públicos, bienes de libre acceso, y en su mayoría son bienes que sufren de algún tipo de externalidad. Estas características han impedido que el mercado sea una buena guía para determinar el nivel eficiente de precio y de cantidad a asignar en la sociedad, y son estas "fallas" en el sistema de mercado que crean la necesidad de utilizar medidas alternativas de valoración económica.

La valoración económica ambiental pretende obtener una medición monetaria de la ganancia o pérdida de bienestar o utilidad que una persona, o un determinado colectivo, experimenta a causa de una mejora o daño de un activo ambiental accesible a dicha persona o colectivo. Constituye por tanto una herramienta fundamental para la definición adecuada de los instrumentos de política ambiental. Ver la Figura 1.

\footnotetext{
* Ingeniero Industrial. Profesor del Departamento Académico de Ingeniería de Sistemas e Informática, UNMSM. E-mail: eraffolecca@yahoo.es

** Ingeniero Industrial. Profesora del Departamento Académico de Ingeniería de Sistemas e Informática, UNMSM. E-mail: rosmahu@hotmail.com
} 
Figura 1. Ejemplos de valoración económica

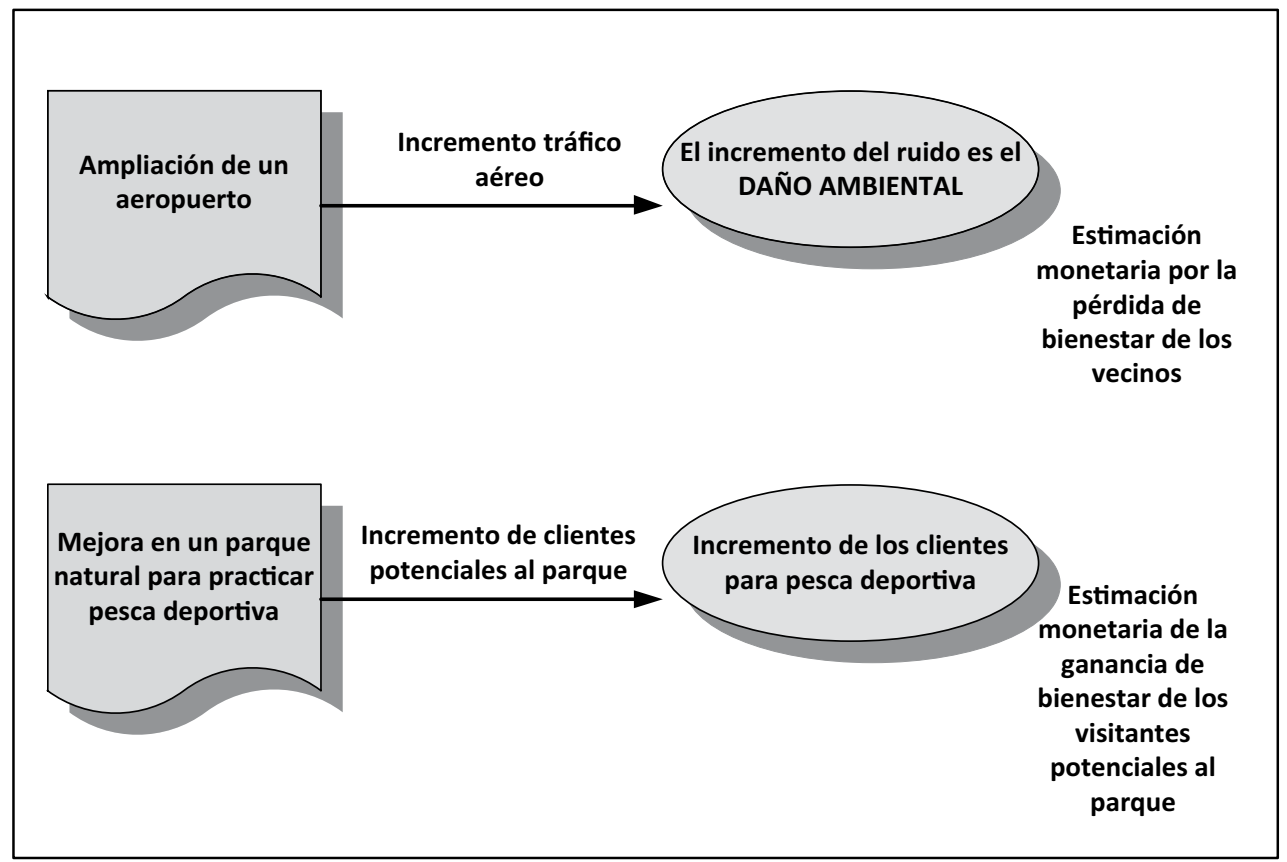

Fuente: Elaboración propia.

La valoración económica ambiental puede definirse formalmente como un conjunto de técnicas y métodos que permiten medir las expectativas de beneficios y costos derivados de algunas de las acciones:

- Uso de un activo ambiental.

- Realización de una mejora ambiental.

- Generación de un daño ambiental.

\section{ANTECEDENTES DE LA INVESTIGACIÓN}

Desde Glave y Pizarro (2001): Muchas veces el mercado subestima el valor económico total de los bienes y servicios ambientales, ya que el valor reflejado en el mercado representa sólo uno de los tantos usos que éste puede tener en el uso directo. Sin embargo, al ser los recursos naturales un capital natural, su uso inadecuado en el presente pone en riesgo el flujo de sus bienes y servicios en el futuro, obviándose en la valoración de mercado de otros usos potenciales: el de uso indirecto, el de opción y el de existencia. Ver la Figura 2.

John Hicks en su obra Valor y Capital (1945), define el ingreso (dinámico) de una persona como el valor máximo que puede consumir durante una semana y encontrarse al final de esta en una situación tan buena como la que tenía al principio. Definición que en los tiempos actuales se ha interpretado como el sustento teórico del ingreso sostenible. El ingreso como preocupación por la pobreza o la posibilidad de consumo; consumo y pobreza, los elementos relevantes de la teoría del desarrollo económico, y ésta, vehículo para el desarrollo sostenible.

Un pozo de petróleo, o un depósito de cobre en el subsuelo, constituyen un activo de capital para la sociedad y su propietario, tal como lo es un edificio o cualquier otro activo de capital renovable. La única diferencia consiste en que el recurso natural no es reproducible, de modo que el tamaño del depósito existente nunca podrá aumentar a través del tiempo. Sólo puede disminuir a no ser que no se explote, esto ocurre hasta con los materiales reciclados que por las leyes de la termodinámica nunca se recupera el total. (Solow, 1974).

Los recursos naturales carecen de precio, por la no existencia de un mercado donde puedan ser intercambiados. No obstante, ello no quiere decir que carezcan de valor. Por tanto, es necesario contar con algún método que nos permita estimar dicho valor o contar con un indicador de su importancia en el bienestar de la sociedad, que permita compararlo con otros componentes del mismo, para lo cual será factible utilizar el dinero como denominador común.

Las externalidades económicas fueron vistas durante mucho tiempo como un aspecto secundario al proceso económico. Efecto-difusión o externalidades son todos aquellos costos 0 beneficios que, aunque resultantes indirectos de 
Figura 2. Conceptualización de valoración económica

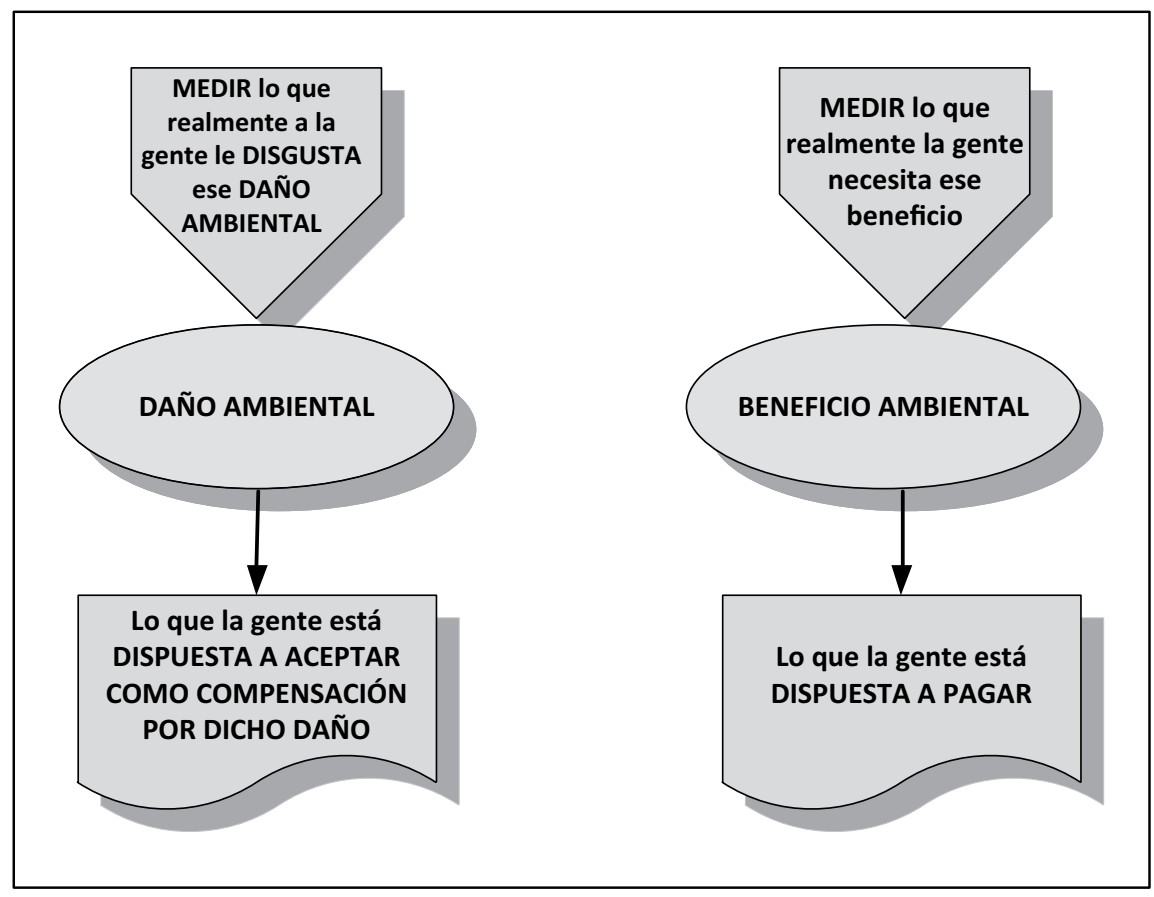

Fuente: Elaboración propia.

un determinado proceso económico son "externos" al mercado específico en que se da este proceso. Alcanzan protagonismo en la ciencia económica a partir de las discusiones en torno de la sostenibilidad ambiental de la economía.

En economía y otras ciencias sociales, una externalidad es, una interdependencia no compensada. Una externalidad positiva se da cuando las acciones de un agente aumentan el bienestar de otros agentes de la economía. Una actividad ayuda o perjudica a personas ajenas a las transacciones de mercado, es decir, se realiza una transacción económica sin un pago económico.

Externalidad negativa se da cuando las acciones de un agente reducen el bienestar de otros agentes de la economía.

Entre las externalidades positivas o beneficio externo se encuentran:

- Desarrollo de zonas urbanas.

- Fuentes de energía eléctrica.

- Actividades como crianza y cultivo.

- Acceso al transporte.

Entre las externalidades negativas o costo externo se encuentran:

- Contaminación de las aguas del cuerpo receptor por residuos sólidos.
- Contaminación de las aguas del cuerpo receptor a causa de las aguas residuales.

- Contaminación de cultivos y suelos con aguas no tratadas del cuerpo receptor.

- Contaminación de las aguas debido a la actividad agropecuaria.

Generalmente los gobiernos se interesan más por las externalidades negativas que por las positivas. La regulación del Estado tiene por objeto controlar algunas externalidades, como los daños causados por las explotaciones mineras a cielo abierto, contaminación del agua y aire, alimentos inseguros y los materiales radiactivos. La conducta de los mercados perfectamente competitivos falla entre otras por las externalidades; así los vertimientos a un cuerpo receptor (ríos y mares), tiene efectos negativos tanto en el ecosistema como la población.

El objetivo principal de la Economía Ambiental (EA) es conducir en forma sistemática una mejor toma de decisiones en la evaluación y gestión económica de los recursos ambientales y naturales. Difícilmente se puede comprender el problema de los impactos que dañan al medio ambiente, así como sus soluciones, sin comprender la relación entre economía y medio ambiente. Algunas cuestiones importantes que estudia la economía ambiental es hasta qué punto las distintas externalidades llevan a una asignación incorrecta de los recursos, cómo podemos mejorar esta asignación y la forma en 
Figura 3. Valor de Uso y No Uso

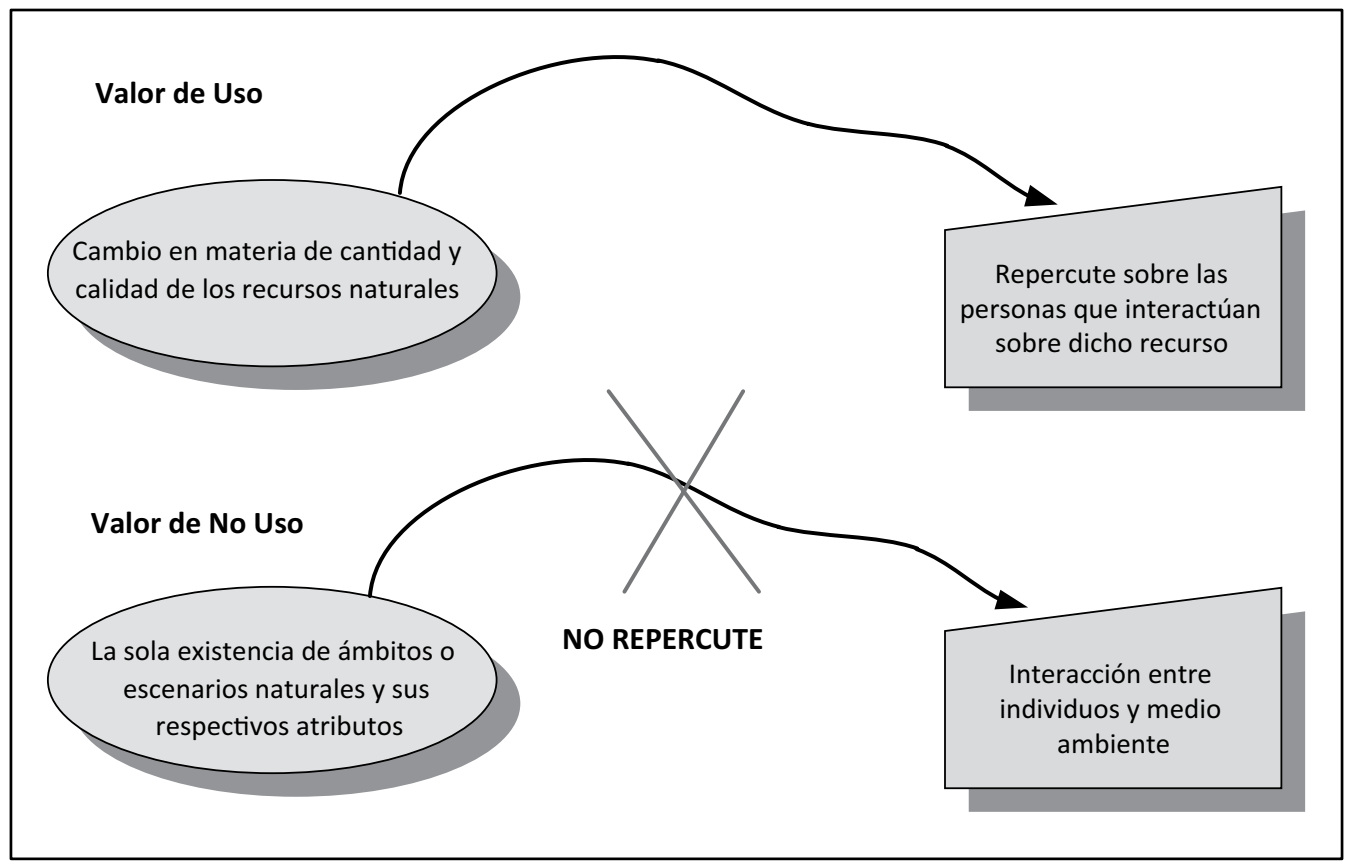

Fuente: Elaboración propia.

que deberíamos hacerlo, porqué lograr un mayor bienestar social. Asimismo, la EA, puede ayudar consistentemente a dar respuesta a problemas acerca de: cómo empleamos y cómo podríamos emplear mejor los recursos naturales, en cuánto valoramos la protección de espacios naturales, cuándo vale la pena realizar un proyecto, cuándo vale la pena construir una carretera, en cuánto deberíamos penalizar a aquellas industrias que dañan nuestro entorno, etc.

El economista John Krutilla (1967) en el trabajo seminal sobre Economía: "Conservation Reconsidered" en American Economic Review, September 1967, p. 777-786, discute muchos de los conceptos que hoy son la base de la Economía Ambiental, y propone el concepto pionero de Valoración Económica Total (VET), definido como la suma de los Valores de Uso y No Uso. Krutilla es considerado el padre de la moderna teoría de la conservación del recurso. Ver la Figura 3.

A través del documento, Krutilla, imagina el cambio entre conservar algunas porciones de tierra para propósitos científicos y/o recreacionales o destruir para extraer recursos tales como los minerales.

EI Valor de Uso es referido al recurso consumido por la actividad que se desarrolla (extracción, caza, pesca), se dice que es de Uso directo; en cambio el valor de Uso indirecto, surge cuando las personas no entran en contacto directo con el recurso en su estado natural, pero aun así el individuo se beneficia de él (las funciones ecológicas o ecosistémicas como regulación de clima, reciclaje de nutrientes y de residuos, formación de suelos, entre otros).

El Valor de No Uso o valor intrínseco sugiere valores que están en la naturaleza real de las cosas, pero a la vez están disociados del uso o incluso de la opción de usarlos. Tal es el caso del valor de la biodiversidad a nivel de especies o de las reservas de capital genético, los cuales existen independientemente de la apreciación de las personas hacia éstos, pero su valor puede ser captado a través de la revelación de las preferencias de estas mismas personas. Se incluye el valor de legado, y el valor de existencia (la satisfacción que produce saber que una especie existe en su hábitat natural.

En la Tabla 1 se presentan las categorías de la valoración económica para los recursos naturales, desde el trabajo de Pearce y Morán: Valoración Económica de la Diversidad.

Los autores Brook y Xepapadeas (2003) en su análisis de diversidad genética para American Economic Review, cuestionan el análisis tradicional de beneficio-costo de Krutilla; presentando la función valor de la biodiversidad asociada con la programación Dinámica, para la representación al problema de planeamiento de un ecosistema. 
Tabla 1. Clasificación de la valoración económica

\begin{tabular}{|c|c|c|c|c|}
\hline \multicolumn{5}{|c|}{ Categorías del Valor Económico atribuible a recursos naturales } \\
\hline \multicolumn{3}{|c|}{ Valor de Uso } & \multicolumn{2}{|c|}{ Valor de No Uso } \\
\hline Uso Directo & Uso indirecto & Valor opción & Valor de legado & Valor de existencia \\
\hline $\begin{array}{l}\text { Productos } \\
\text { directamente } \\
\text { consumibles }\end{array}$ & $\begin{array}{l}\text { Beneficios derivados } \\
\text { de funciones } \\
\text { ecosistémicas }\end{array}$ & $\begin{array}{l}\text { Valores futuros } \\
\text { directos e indirectos }\end{array}$ & $\begin{array}{l}\text { Valores de Uso y } \\
\text { No Uso del legado } \\
\text { ambiental }\end{array}$ & $\begin{array}{l}\text { Valor de conocer } \\
\text { que todavía existe } \\
\text { un componente del } \\
\text { medio ambiente }\end{array}$ \\
\hline $\begin{array}{l}\text { Alimentos, biomasa, } \\
\text { recreación, salud, } \\
\text { entre otros }\end{array}$ & $\begin{array}{l}\text { Control de clima, de } \\
\text { suelos, de reciclaje, } \\
\text { de nutrientes, entre } \\
\text { otros }\end{array}$ & $\begin{array}{l}\text { Bioprospección, } \\
\text { conservación de } \\
\text { hábitats, entre otros }\end{array}$ & $\begin{array}{l}\text { Prevención de } \\
\text { hábitats, de cambios } \\
\text { irreversibles, entre } \\
\text { otros }\end{array}$ & $\begin{array}{l}\text { Hábitat, especies, } \\
\text { genes, ecosistemas, } \\
\text { entre otros }\end{array}$ \\
\hline
\end{tabular}

Fuente: Pearce, David W. y D. Morán (1994)

\section{ECONOMÍA AMBIENTAL Y ECONOMÍA ECO- LÓGICA}

La economía es la ciencia que estudia el comportamiento humano como una relación entre fines y bienes escasos con usos alternativos (Robbins, 1935). De la definición tradicional se desprende que la economía se dedica a la asignación de recursos escasos, susceptibles de usos alternativos para la satisfacción de las necesidades. En el tiempo el bien medioambiente dejó de ser un bien libre para convertirse en un bien escaso.

La Economía Ambiental o EA no es la aplicación de las ciencias económicas en general a la problemática ambiental. La EA es la interpretación de la escuela del pensamiento económico denominada Escuela Neoclásica (EN), que pasó a incorporar el medio ambiente como objeto de estudio. La EA se basa, en los mismos conceptos y supuestos básicos de la EN, que concentra el análisis sobre la escasez, y donde los bienes son valorados por su abundancia o escasez. Cuando se trata de bienes escasos o valiosos, éstos son considerados bienes económicos, en caso contrario, no son económicos. La EA va más allá de los límites de la EN ortodoxa.

Los recursos naturales son aquella parte de la Naturaleza que tiene alguna utilidad o potencial de uso para el hombre, es decir, son los elementos naturales que el ser humano aprovecha para satisfacer sus necesidades materiales o espirituales. Los recursos naturales, en función de su capacidad de autorrenovación, se diferencian en renovables y no renovables.

En el ambiente o medio ambiente, recursos naturales como el agua, algunas fuentes de energía y la diversidad biológica, comienzan a perder su calificativo de ser renovable y presentar un futuro de agotamiento. También, estos bienes naturales, insumos indispensables del proceso productivo, presentan características de bienes no económicos, por no poseer precio, ni dueño. Por esta razón, el medio ambiente se encuentra externo al mercado. La incorporación del medio ambiente al mercado se daría mediante el procedimiento de internalización de esas externalidades, adjudicándoles un precio. En consecuencia, la EA se ocupa principalmente de la valoración monetaria del medio ambiente. Una vez internalizado, el medio ambiente pasa a tener las características de un bien económico, o sea, pasa a tener precio y/o derecho de propiedad.

La EA, además, se ocupa de estudiar las maneras como se pueden cambiar las políticas e instituciones económicas con el propósito de equilibrar un poco más esos impactos ambientales con los deseos humanos y las necesidades del ecosistema en sí mismo (Field, Barry, Diego Azqueta Oyarzum, 1998).

A lo largo de la historia, la problemática ambiental estuvo variando conforme al pensamiento económico. Así Francis Bacón en el siglo XVII expresaba que la naturaleza debía ser puesta al servicio del hombre. Teoría que hoy en día implicaría una naturaleza insustentable, en donde el ecosistema perdería su capacidad para mantenerse frente a alteraciones exteriores. El margen de resiliencia.

Quesnay y los fisiócratas consideraban que la fuente de todas las riquezas del Estado y de los ciudadanos era la agricultura, porque sólo ella restituía al hombre más valor del que fue invertido. La fisiocracia, que significa "el poder de la tierra", concibe a la economía humana dentro de la 
naturaleza, y que el hombre debe respetar los ciclos y equilibrios, si desea continuar aprovechando la gratuidad de sus dones.

A finales del siglo XVIII, por primera vez en forma explícita, los economistas clásicos (David Ricardo, Thomas R. Malthus, Adam Smith, entre otros) inauguraron la época de la finitud de los recursos naturales. Tanto la teoría de la dinámica demográfica del reverendo Malthus, como la teoría de los rendimientos decrecientes de la tierra de David Ricardo, apuntan al límite ambiental que significaría la insuficiente oferta de tierras de buena calidad. En Ensayo sobre el principio de la población (1798), T. R. Malthus plantea la ciencia sombría con respecto a la población y las limitaciones de recursos; vigente en nuestros días para explicar la lucha entre las poblaciones (como India, Nigeria) y las existencias de alimentos

Desde A. Smith a finales del siglo XVIII, la ciencia económica moderna se ha preocupado de estudiar la asignación de los recursos escasos para propósitos alternativos por medio del sistema de precios en el mercado: el verdadero valor de las cosas estaba en lo que costaba producirlas. Para A. Smith la palabra Valor tenía dos significados muy opuestos, "valor de uso" y "valor de cambio". Las cosas con mayor valor de cambio tienen con frecuencia poco o ningún valor de uso.

Hace más de 200 años, Adam Smith planteó en La riqueza de las naciones (1776) la paradoja del valor: "Nada es más útil que el agua; pero apenas se puede comprar nada con ella. En cambio, un diamante apenas tiene valor de uso, pero a menudo es posible intercambiarlo por una gran cantidad de bienes" (Samuelson, 2004).

La respuesta a la paradoja de Adam Smith es que la curva de oferta y demanda para el agua se cortan en un precio muy bajo, mientras que la del diamante su precio de equilibrio es muy alto.

En el siglo XIX, la Revolución Industrial, basada en la termodinámica o potencia motriz del calor, marca una ruptura en la cuestión ecológica. Con la revolución técnico-científica aplicada a la producción, la problemática ambiental se extiende a una escala geográfica cada vez mayor. En esta etapa aparecen precursores de la Economía Ecológica (EE), quienes basándose en principios de la termodinámica, demuestran las repercusiones ecológicas de la revolución "termo-industrial", consistentes en trastornos irreversibles en los grandes ciclos de la biosfera.

A mediados del siglo XIX, A. Dupuit (1804-1866) conceptualiza la medida del valor. "La curva de la demanda corresponde a la máxima disposición a pagar por sucesivas unidades del bien o el máximo sacrificio expresado en dinero que cada consumidor está dispuesto a realizar para adquirir un bien" ( $P$. Riera y otros, 2011).

A finales del siglo XIX, los economistas comprendieron que toda acción económica tiene efectos que van más allá del horizonte de la racionalidad mercantil individual, lo que llevó a Alfred Marshall a hablar de economías externas.

En el periodo de posguerra (1950 a 1973), la economía mundial experimenta un crecimiento vertiginoso de la producción, con tasas de productividad de la mano de obra elevada y continua, impulsadas por la tecnología basada en la electrónica y los nuevos químicos. Es en estos tiempos donde se pone en duda la relación entre crecimiento económico y aumento del bienestar.

La discusión sobre la cuestión ambiental toma fuerza en los años ochenta-noventa, en los que se vuelve cada vez más evidente que el aumento de la producción va acompañado de una intensificación de la degradación ambiental, que pasa a adquirir dimensiones globales. Al mismo tiempo, algunos de los problemas ambientales más graves se vuelven cada vez más perceptibles a los ojos humanos, como lo son la pérdida de la biodiversidad, el agujero de la capa de ozono, o los cambios climáticos.

La EA nace con el estudio del valor económico de las externalidades ambientales a partir de los años 1970 , donde se destaca la importancia y magnitud de las externalidades ambientales asociadas al proceso del desarrollo económico.

La EA es la respuesta de la EN a la problemática ambiental contemporánea. Esta disciplina se basa en las teorías de la internalización de las externalidades de Arthur Cecil Pigou (1877-1959) y Ronald Coase (1910), ambos de la EN.

Hasta antes de Coase, se consideraba importante el hecho de que el causante o la víctima de la contaminación sea el propietario del recurso contaminado.

Ronald $\mathrm{H}$. Coase en su trabajo El problema del costo social, examina el problema de las acciones de las empresas que tienen efectos perjudiciales a terceros. Coase concibe el problema como de naturaleza recíproca.

En su análisis el sistema de costos con responsabilidad con daños y sin daños, arriba a la conclusión que el problema consiste en evitar el perjuicio más grave. 
En el seno de la organización, los costos administrativos de las transacciones (recursos usados para establecer y mantener los derechos de propiedad) pueden ser elevados, de allí que Coase propone al Estado (como una superempresa) capaz de influir sobre el empleo de los factores de producción, con la finalidad de expropiar bienes, y decretar qué factores de producción sólo deben usarse de tal o cual modo (Teorema de Coase, 1960).

La idea de Coase se basa en que si los derechos de propiedad están perfectamente definidos, el aire, la tierra y el aire son mercancías que pueden comprarse y venderse en el mercado. La garantía de los derechos de propiedad trae como consecuencia la eliminación de las externalidades.

En el caso de una empresa que vierte sus residuos a un río, la empresa externaliza los costos generados por los vertidos. Los pescadores al tener el derecho de propiedad sobre el agua limpia, podrían exigir a la empresa que les pague por el derecho de vertidos. La empresa pagaría por los costos ocasionados por los residuos; entonces estos costos se internalizarían.

La EA estudia habitualmente dos cuestiones: el problema de las externalidades y la asignación intergeneracional óptima de los recursos agotables (Aguilera, F y V. Alcántara, 2011).

La Economía Ecológica (EE) surge como crítica a la $E A$, basada en las leyes de la termodinámica y los grandes ciclos de los ecosistemas de la biosfera. Esta escuela vuelve a enfatizar la finitud de los recursos naturales en las propuestas de política de gestión ambiental.

Desde la primera ley de la termodinámica: el total de energía y materia se mantienen constantes en los sistemas cerrados; lo que se toma de la naturaleza y lo que se devuelve, no siempre tiene la misma estructura o forma.

Desde la segunda ley de la termodinámica, la ley de la entropía: cuanto menos estructurada esté la energía y la materia, mayor será la entropía en el sistema, y menos será utilizada; y cuando menor sea la entropía en el sistema, mayor serán las posibilidades de uso.

La EA analiza cuatro aspectos:

- Las externalidades ambientales.

- La insuficiencia de mercados eficientes para muchos bienes ambientales.

- La ausencia de derechos de propiedad claramente definidos.

- La realización de valoraciones monetarias del medioambiente.
Figura 4. Disponibilidad para pagar.

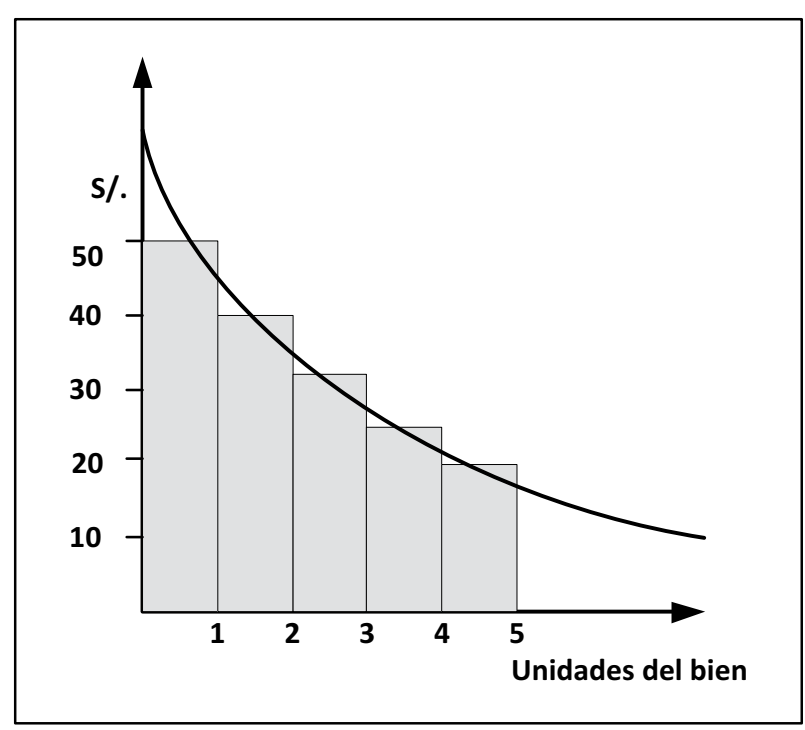

Fuente: Elaboración propia.

\section{HERRAMIENTAS ANALÍTICAS}

Las acciones económicas que incluyen actividades ambientales tienen dos aspectos: crean valor y por otra enfrentan costos (Field, Barry, Diego Azqueta Oyarzum, 1998).

Figura 5. Demanda/Disponibilidad marginal para pagar.

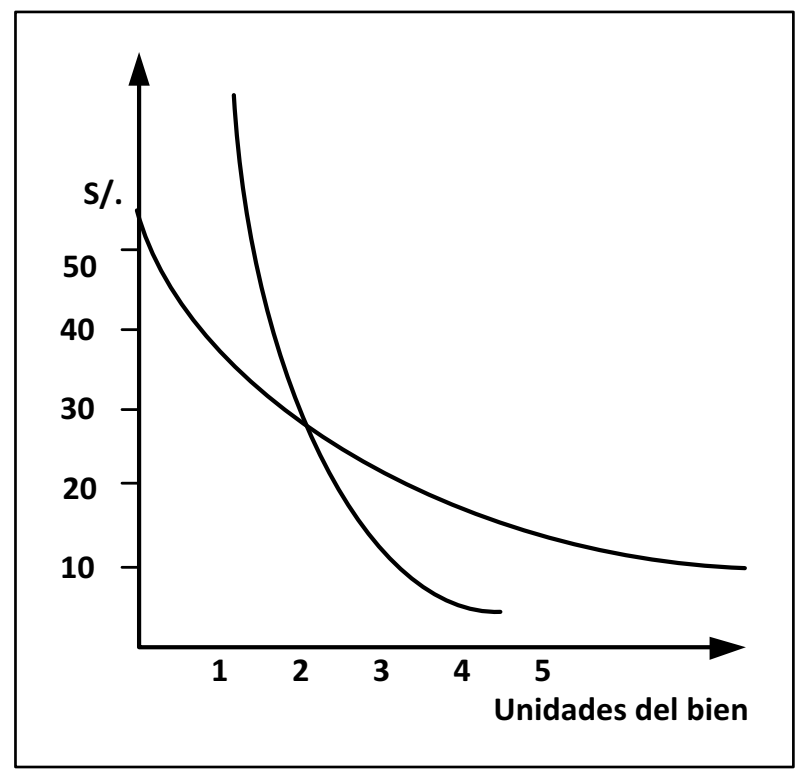

Fuente: Elaboración propia. 
La disponibilidad por pagar se basa en la noción fundamental de que los individuos tienen preferencias por bienes y servicios; ante una elección, ellos pueden expresar preferencias por un bien sobre otro.

El valor de un bien para una persona, es lo que está dispuesto a pagar y puede sacrificar para conseguirlo. El valor de un bien es lo que la persona está en disposición de sacrificar una cantidad de dinero. La disponibilidad para pagar también refleja la capacidad de pago.

En la Figura 4, se presenta la gráfica de la disponibilidad para pagar de una persona por un bien. Se observa que paga S/ 50 por una unidad; S/ 40 por la segunda unidad; S/ 32 por la tercera unidad y S/ 25 por la cuarta unidad. El total pagado por las cuatro unidades es $50+40+32+25$ igual a $S / 147$. Se concluye que a medida que aumenta la cantidad de unidades, disminuye la disponibilidad para pagar de unidades adicionales de ese bien. La cantidad de S/ 147 es la disponibilidad total para pagar el consumo de cuatro unidades; y S/ 25 es la disponibilidad marginal para pagar por la cuarta unidad.

Las curvas de demanda son otra forma de presentar las relaciones de disponibilidad marginales para pagar. En la Figura 5 se observa dos curvas de demandas diferentes; la de la izquierda de menor pendiente y la disponibilidad marginal para pagar decrece lentamente a diferencia de la curva de la derecha con mayor pendiente y decrecimiento rápido. La gráfica podría ser la curva de demanda para dos personas frente al mismo producto, o de una persona frente al mismo producto en dos momentos diferentes.

Se denomina curva de demanda agregada a la sumatoria de curvas de demandas individuales.

Los beneficios están ligados al término hacerse mejor. En el caso de una mejora en la contaminación existen beneficios en las persona; y en el caso del deterioro de la calidad ambiental se le priva de los beneficios. Los beneficios están asociados al suministro de algo que la persona valora y que está dispuesta a pagar. Los beneficios que obtienen las personas, son iguales a la cantidad que se están dispuestas a pagar.

Cuanto más valoran las personas algo, mayores beneficios obtienen cuando obtienen más de ese algo disponible.

El costo privado de producción es el costo que carga el productor por un bien o servicio; el costo marginal privado (CM) es el costo de producir una unidad adicional de un bien o servicio. El costo marginal externo es el costo de producir una unidad adicional de un bien o servicio que recae a otras personas diferentes del productor.
La suma del costo marginal privado y el costo marginal externo es el costo marginal social (CMS) que recae en toda la sociedad. El costo marginal externo es el costo de la externalidad, por una calidad ambiental:

$$
\mathrm{CMS}=\mathrm{CM}+\text { Costo marginal externo }
$$

La valoración del costo marginal externo es consecuencia del costo de la contaminación del río, en el caso de los costos ocasionados por los residuos vertidos.

Figura 6. El costo marginal social.

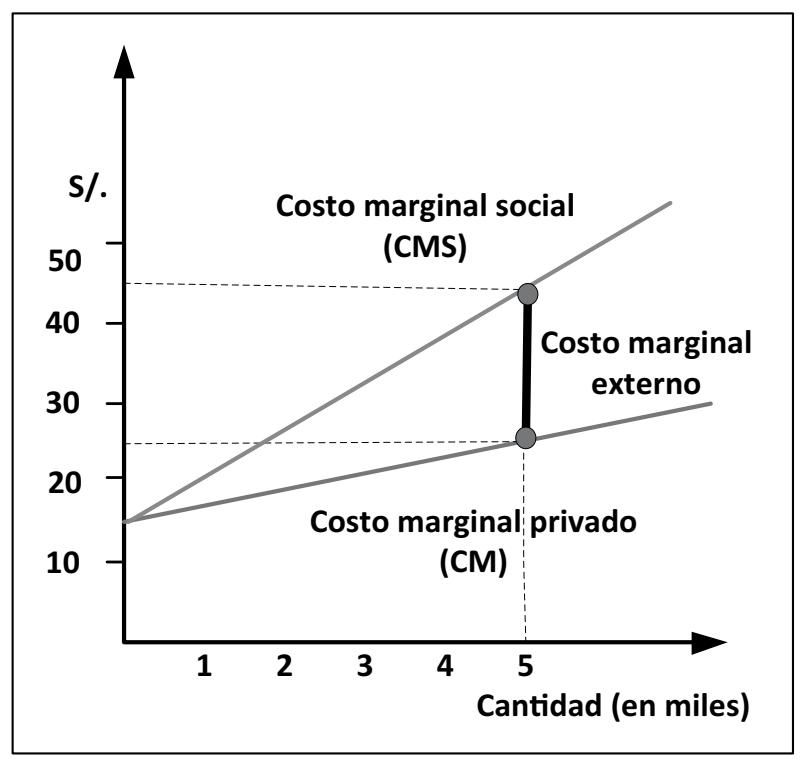

Fuente: Elaboración propia.

Figura 7. Equilibrio eficiente.

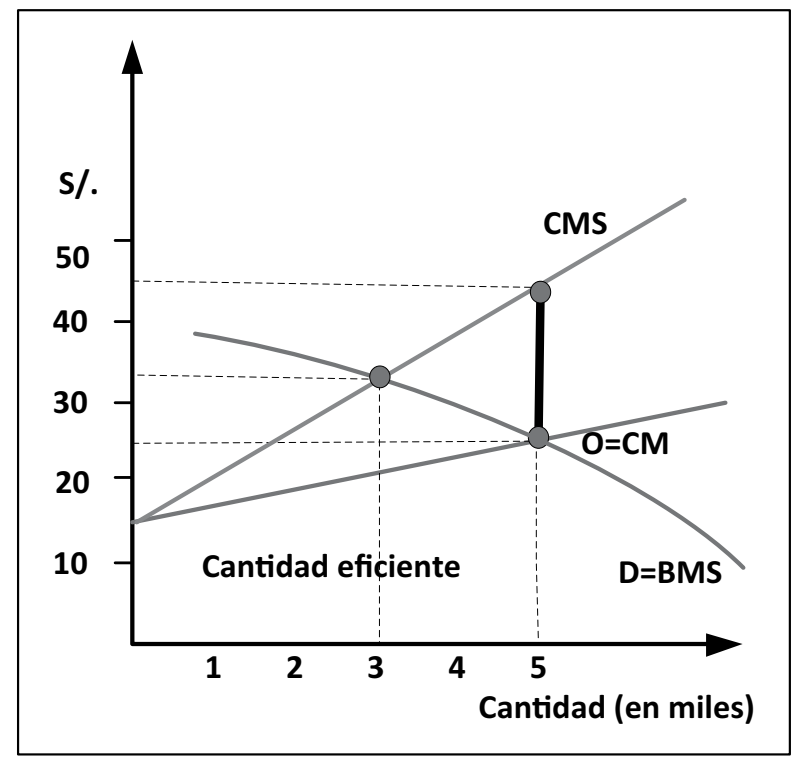

Fuente: Elaboración propia. 
En la figura 6, se presenta la situación de producir 5 mil unidades con el costo marginal privado de $\mathrm{S} / .25$ y el costo marginal externo de S/.20. El costo marginal social es $S / .45$ para 5,000 unidades y se incrementa a medida que aumentan las unidades producidas.

En la figura 7, la curva de oferta es el costo marginal privado y la curva de demanda es el beneficio marginal social (BMS). La cantidad eficiente es 3000 unidades a un precio de $S / .35$.

El equilibrio de mercado de 4 mil unidades a un precio de $\mathrm{S} / .25$ es ineficiente. La asignación de recursos es eficiente cuando el beneficio marginal social es igual al costo marginal social.

Desde la Figura 7 considerando los derechos de propiedad, se interpreta que el costo de la contaminación recae sobre el responsable de contaminar y la curva CMS se convierte en la curva del costo marginal privado (Parkin, 2009).

\section{TÉCNICAS DE LA VALORACIÓN ECONÓMICA}

Las técnicas de valoración ambiental pretenden obtener la disposición a pagar por un cambio positivo en un bien ambiental o la disposición a aceptar una compensación por un cambio negativo.

La EA se centra, en dos ámbitos básicos: el campo de la valoración (estudios de impacto y de costo ambiental, para lo que utiliza una serie de instrumentos y metodologías como los estudios de coste/beneficio, la valoración contingente, la disponibilidad a pagar, etc.) y el campo de la política y gestión ambiental, donde propone diversos instrumentos de política fiscal ambiental, constitución de mercados secundarios, políticas y gestión ambiental.

Uno de los temas más interesantes de la EA consiste en la explicación de los impactos ambientales que se ocasiona con la actividad económica. Tales impactos ambientales frecuentemente no pasan por el mercado y, por tanto, no se observa el precio que tiene en cuenta el costo adicional de contaminación generada por las actividades. Estos costos adicionales los tienen que pagar aquellos actores que causan la emisión de la contaminación, la cual se conoce como externalidad negativa o costo externo.

Las técnicas de valoración económica pueden clasificarse de la siguiente manera:

a. Métodos de mercado o directos: productividad marginal, gastos de mitigación, costos de oportunidad, gastos en salud, gastos defensivos. b. Métodos de valoración de no mercado o indirectos: Estos métodos pueden a su vez sub-clasificarse en:

- Métodos de preferencias reveladasmercados subrogados: En ausencia de mercados para los servicios a valorar se estiman precios sombra a partir de otros bienes y servicios que si poseen mercados y están relacionados con el recurso objetivo sobre el cual se desea medir el atributo ambiental

- Métodos de preferencias declaradasmercados hipotéticos: En ausencia de mercados para los servicios a valorar se recurre a la simulación o creación de un mercado hipotético. A través de esta técnica siempre es posible obtener una medida de valoración.

c. Transferencia de valores: utiliza estimaciones de otros estudios realizados para problemas similares y que, dependiendo de su calidad y del proceso de transferencia elegido, han sido reconocidos por la literatura científica como fiables.

\section{VALORACIÓN ECONÓMICA EN LA LEGISLA- CIÓN DEL PERÚ}

En el Artículo 2 numeral 2.3 de la Ley General del Ambiente (LGA) Ley $N^{\circ} 28611$ se encuentra: Que toda mención hecha al "ambiente" o a "sus componentes" comprende a los elementos físicos, químicos y biológicos de origen natural o antropogénico que, en forma individual o asociada, conforman el medio en el que se desarrolla la vida, siendo los factores que aseguran la salud individual y colectiva de las personas y la conservación de los recursos naturales, la diversidad biológica y el patrimonio cultural asociado a ellos, entre otros.

Los servicios ambientales son los beneficios que proporcionan a los seres humanos las funciones de los ecosistemas y demás componentes del ambiente, sea porque le proveen de bienes y condiciones necesarios para el desarrollo de su vida o porque impiden eventos que la ponen en riesgo o disminuyen su calidad. Los bienes ambientales son los recursos tangibles que son utilizados por el ser humano como insumos en la producción o en el consumo final, y que se gastan y se transforman en el proceso. Los impactos ambientales o las externalidades, son la consecuencia de la actividad económica de una persona sobre el bienestar de otra. 
Desde la LGA en su Artículo 94.- De los servicios ambientales se encuentra:

94.1 Los recursos naturales y demás componentes del ambiente cumplen funciones que permiten mantener las condiciones de los ecosistemas y del ambiente, generando beneficios que se aprovechan sin que medie retribución o compensación, por lo que el Estado establece mecanismos para valorizar, retribuir y mantener la provisión de dichos servicios ambientales, procurando lograr la conservación de los ecosistemas, la diversidad biológica y los demás recursos naturales.

94.2 Se entiende por servicios ambientales, la protección del recurso hídrico, la protección de la biodiversidad, la mitigación de emisiones de gases de efecto invernadero y la belleza escénica, entre otros.

94.3 La Autoridad Ambiental Nacional promueve la creación de mecanismos de financiamiento, pago y supervisión de servicios ambientales.

Las funciones de un ecosistema son los procesos biofísicos que tienen lugar en ese ecosistema y que benefician a los seres humanos (mejor caza, agua más dulce, mejores paisajes, polinización gratuita, áreas seguras o menos vulnerables a los desastres naturales, menor calentamiento global, suelos más productivos, entre otros); según El Manual del Derecho Ambiental (Andaluz, Carlos, 2011).

En la Ley 28611, Ley General Del Ambiente, Título Preliminar Derechos y Principios el texto de los Artículos VIII y IX son los siguientes:

\section{Artículo VIII.- Del principio de internalización de costos}

Toda persona natural o jurídica, pública o privada, debe asumir el costo de los riesgos o daños que genere sobre el ambiente.

El costo de las acciones de prevención, vigilancia, restauración, rehabilitación, reparación y la eventual compensación, relacionadas con la protección del ambiente y de sus componentes de los impactos negativos de las actividades humanas debe ser asumido por los causantes de dichos impactos.

\section{Artículo IX.- Del principio de responsabilidad ambiental \\ El causante de la degradación del ambiente y de sus componentes, sea una persona natural o jurídica, pública o privada, está obligado a}

adoptar inexcusablemente las medidas para su restauración, rehabilitación o reparación según corresponda o, cuando lo anterior no fuera posible, a compensar en términos ambientales los daños generados, sin perjuicio de otras responsabilidades administrativas, civiles 0 penales a que hubiera lugar.

En la ley 27466, Ley del Sistema Nacional de Evaluación de Impacto Ambiental, el Artículo 10.- Contenido de los Instrumentos de Gestión Ambiental (modificado por el Artículo 1 del Decreto Legislativo $\mathbf{N}^{0}$ 1078), el texto en el numeral 10.1 literal $f$ es el siguiente:

Los estudios de impacto ambiental deberán contener la valorización económica del impacto ambiental.

En el Reglamento de la Ley 27466, Ley del Sistema Nacional de Evaluación de Impacto Ambiental, DS-019-2009-MINAM se encuentra el Artículo 26.Valorización económica del impacto ambiental de proyectos de inversión:

Para valorizar económicamente el impacto ambiental en los estudios ambientales debe considerarse el daño ambiental generado, el costo de la mitigación, control, remediación o rehabilitación ambiental que sean requeridos, así como el costo de las medidas de manejo ambiental y compensaciones que pudieran corresponder, entre otros criterios que resulten relevantes de acuerdo al caso.

\section{REFERENCIAS BIBLIOGRÁFICAS}

[1] Aguilera, F., V. Alcántara (2011). "De la Economía Ambiental a la Economía Ecológica". Barcelona, España: CIP-Ecosocial, Edición electrónica revisada.

[2] Andaluz, Carlos (2011). "El Manual del Derecho Ambiental". Lima, Perú: Editorial IUSTITIA S.A.C.

[3] Coase, Ronald (1960). "The Problem of Social Cost”. The Journal of Law and Economics, 3.

[4] Glave, Manuel y Rodrigo Pizarro. Editores. (2001)."Valoración Económica de la Diversidad Biológica y servicios Ambientales en el Perú".

[5] Barzev, Rado. (2012)."Valoración Económica Integral de los Bienes y Servicios Ambientales de la Reserva del Hombre y la Biósfera del plátano". Tegucigalpa: Honduras. 
[6] Field, Barry, Diego Azqueta Oyarzum (1998). Economía \& Medio Ambiente. McGraw-Hill. Santafé de Bogotá D.C., Colombia: Tomos 1,2 y 3 .

[7] Hicks, John (1974). "Valor y Capital". México, D.F., México: Fondo de Cultura Económica.

[8] Jacobs, M. (1991). "Green Economic Environment Sustainable Developments and the politics of the future". London.

[9] Krutilla, John. (1967). "Conservation reconsidered", en American Economic Review, 57(4).

[10] Pearce, David W. y D. Morán (1994). "The Economic Value of Diversity". UICN. Londres.

[11] Pearce, David W y R. Kerry Turner (1990). "Economics of Natural Resources and the Environment". The Johns Hopkins University Press, Maryland.
[12] Parkin, Michael (2009). "Economía”. México D.F., México: Pearson Educación, Octava edición.

[13] Riera, P., D. García, B. Kristrom, R. Braunnlund (2011). "Manual de Economía Ambiental y de los Recursos naturales". Madrid, España: Paraninfo, Tercera reimpresión.

[14] Samuelson, Paul, William Nordhaus, José Salazar, Raymundo Rodríguez (2004). "Microeconomía con aplicaciones a Latinoamérica”. México, D. F., México: McGraw-Hill Interamericana, Decimoséptima edición.

[15] Solow, Robert (1974). "The Economics of Resource or the Resources of Economics". The American Economic Review, vol. 64, pp. 1-14. Versión en castellano en El Trimestre Económico, vol. XLII (2), N N 166, Abril-Junio, 1975. 